\title{
A case of idiopathic type 1 diabetes with subsequent recovery of endogenous insulin secretion despite initial diagnosis of fulminant type 1 diabetes
}

\author{
Keizo Kaneko, Chihiro Satake, Junpei Yamamoto, Hironori Takahashi, Shojiro Sawada, Junta Imai, \\ Tetsuya Yamada and Hideki Katagiri
}

Department of Diabetes and Metabolism, Tohoku University Hospital, Sendai 980-8575, Japan

\begin{abstract}
Fulminant type 1 diabetes is characterized by remarkably rapid and complete $\beta$-cell destruction. The established diagnostic criteria include the occurrence of diabetic ketosis soon after the onset of hyperglycemic symptoms, elevated plasma glucose with relatively low HbAlc at the first visit, and extremely low C-peptide. Serum C-peptide levels remain extremely low over a prolonged period. A 26-year-old-man with diabetic ketosis was admitted to our hospital. His relatively low HbA1c (7.6\%), despite marked hyperglycemia $(593 \mathrm{mg} / \mathrm{dL})$ with marked ketosis, indicated abrupt onset. Islet-related autoantibodies were all negative. His data at onset, including extremely low serum C-peptide $(0.11 \mathrm{ng} / \mathrm{mL})$, fulfilled the diagnostic criteria for fulminant type 1 diabetes. However, his fasting serum C-peptide levels subsequently showed substantial recovery. While fasting C-peptide stayed below $0.30 \mathrm{ng} / \mathrm{mL}$ during the first two months post onset, the levels gradually increased and thereafter fluctuated between $0.60 \mathrm{ng} / \mathrm{mL}$ and $0.90 \mathrm{ng} / \mathrm{mL}$ until 24 months post onset. By means of multiple daily insulin injection therapy, his glycemic control has been well maintained (HbAlc approximately $6.0 \%$ ), with relatively small glycemic fluctuations evaluated by continuous glucose monitoring. This clinical course suggests that, despite the abrupt diabetes onset with extremely low C-peptide levels, substantial numbers of $\beta$-cells had been spared destruction and their function later showed gradual recovery. Diabetes has come to be considered a much more heterogeneous disease than the present subdivisions suggest. This case does not fit into the existing concepts of either fulminant type 1 or ketosis-prone diabetes, thereby further highlighting the heterogeneity of idiopathic type 1 diabetes.
\end{abstract}

Key words: Idiopathic type 1 diabetes, Fulminant type 1 diabetes, Classification

IDIOPATHIC TYPE 1 DIABETES is regarded as a heterogeneous autoantibody-negative insulin-deficient form of diabetes. There have been a number of studies and cases showing the genetic and/or clinical heterogeneity of this disorder, which have enhanced our better understanding of its etiology, diagnosis and prognosis $[1,2]$. In addition, fulminant type 1 diabetes, a distinct clinical subtype of idiopathic type 1 diabetes, has been widely recognized. Fulminant type 1 diabetes was originally proposed as a disease characterized by remarkably rapid and almost complete $\beta$-cell destruction [3]. The established diagnostic criteria are: (A) occurrence of diabetic ketosis or ketoacidosis soon (around 7 days) after the onset of hyperglycemic

Submitted May 10, 2016; Accepted Nov. 21, 2016 as EJ16-0245 Released online in J-STAGE as advance publication Jan. 6, 2017 Correspondence to: Hideki Katagiri, M.D., Ph.D., Department of Diabetes and Metabolism, Tohoku University Hospital, 2-1 Seiryo, Aoba-ku, Sendai, Miyagi 980-8575, Japan.

E-mail: katagiri@med.tohoku.ac.jp symptoms documented at the first visit (B) plasma glucose $\geq 288 \mathrm{mg} / \mathrm{dL}$ and $\mathrm{HbA} 1 \mathrm{c}<8.7 \%$ at the first visit (C) serum C-peptide level $<0.30 \mathrm{ng} / \mathrm{mL}$ at fasting and $<0.50 \mathrm{ng} / \mathrm{mL}$ after an intravenous glucagon load at the onset. Other findings such as undetectable islet-related autoantibodies and flu-like symptoms prior to the disease onset are often seen $[3,4]$. In addition, elevations of serum pancreatic enzymes (amylase, lipase or elastase-1) are observed in $98 \%$ of these patients. A combination of genetic (e.g. certain HLA haplotypes) and environmental (e.g. viral infection) factors are hypothesized to trigger rapid and transient immune cell infiltration of pancreatic islets, destroying nearly all $\beta$-cells [3]. Serum C-peptide in patients with fulminant type 1 diabetes reportedly remains undetectable or persists at extremely low levels $(<0.30 \mathrm{ng} / \mathrm{mL})$ after the onset [5]. Since islet-related autoantibodies are generally undetectable, fulminant type 1 diabetes is typically classified into one of the subcategories of idiopathic type 1 diabetes. We recently experienced an interesting case 
of idiopathic type 1 diabetes with sparing of absolute $\beta$-cell destruction despite fulfilling the diagnostic criteria for fulminant type 1 diabetes at onset.

\section{Case Presentation}

A 26-year-old-man with diabetic ketosis was admitted to our hospital. Hyperglycemia had never been detected on regular check-ups and he had no family history of diabetes. He had no history of excessive soft-drink ingestion. Ten days after catching a cold, he had presented with sudden onsets of thirst, polyuria and general fatigue. On admission, his height and weight were $1.78 \mathrm{~m}$ and $63.7 \mathrm{~kg}$, respectively (body mass index $20 \mathrm{~kg} / \mathrm{m}^{2}$ ). He had lost $5 \mathrm{~kg}$ during the prior week. Arterial blood gas analysis showed $\mathrm{pH}$ 7.334, $\mathrm{pCO}_{2} 36.7 \mathrm{mmHg}, \mathrm{pO}_{2} 108 \mathrm{mmHg}, \mathrm{O}_{2}$ saturation $95.4 \%$ and bicarbonate $19.0 \mathrm{mEq} / \mathrm{L}$. While HbA1c was relatively low (7.6\%), serum glucose and glycoalbumin were very high $(593 \mathrm{mg} / \mathrm{dL}$ and $29.2 \%$, respectively) with marked ketosis: $\beta$-hydroxybutyric acid was $6,321 \mu \mathrm{mol} / \mathrm{L}$ and acetoacetate was 1,250 $\mu \mathrm{mol} / \mathrm{L}$, indicating very abrupt onset of diabetes. Islet-related autoantibodies, such as those against GAD, insulin, IA-2 and ZnT8, were all negative. Serum levels of pancreatic enzymes, including lipase (208 U/L) and elastase-1 (1,240 ng/dL), were elevated, although abdominal computed tomography revealed no findings of pancreatitis. Urinary tests showed neither proteinuria nor albuminuria. Fasting and 6-minute post-glucagon-stimulated serum C-peptide levels were $0.11 \mathrm{ng} / \mathrm{mL}$ and $0.16 \mathrm{ng} / \mathrm{mL}$, respectively. These findings (Table 1) met the criteria for a diagnosis of fulminant type 1 diabetes. In addition, his human leukocyte antigen (HLA) genotype was DRB $1 * 04: 05-\mathrm{DQB} 1 * 04: 01$, which is frequently observed in fulminant type 1 diabetes. No significant elevation of viral antibody titers, such as those for influenza B, coxsackie B3 and B4, herpes simplex and Epstein-Barr virus, were detected 2 weeks or more after the onset. Intravenous insulin treatment followed by subcutaneous multiple daily insulin injection therapy (MDI) achieved good glycemic control. After discharge, we monitored his fasting serum C-peptide levels for 24 months (Fig. 1). During the first two months post onset (MPO), C-peptide levels stayed between 0.11 and $0.28 \mathrm{ng} / \mathrm{mL}$. Interestingly, at 3 MPO, his C-peptide levels exceeded $0.30 \mathrm{ng} / \mathrm{mL}$ and thereafter fluctuated between approximately 0.50
Table 1 Data on Admission

\begin{tabular}{|c|c|c|}
\hline & & Normal range \\
\hline Patient weight (kg) & 63.7 & \\
\hline Body mass index $\left(\mathrm{kg} / \mathrm{m}^{2}\right)$ & 20 & \\
\hline \multicolumn{3}{|l|}{ Blood chemistry } \\
\hline Glucose (mg/dL) & 593 & \\
\hline HbA1c $(\%)$ & 7.6 & \\
\hline Glycoalbumin (\%) & 29.2 & \\
\hline$\beta$-hydroxybutyric acid $(\mu \mathrm{mol} / \mathrm{L})$ & 6,321 & $0-74$ \\
\hline Acetoacetate $(\mu \mathrm{mol} / \mathrm{L})$ & 1,250 & $28-46$ \\
\hline Amylase (U/L) & 93 & $37-125$ \\
\hline Lipase (U/L) & 208 & $6-48$ \\
\hline Elastase one (ng/dL) & 1,240 & $100-400$ \\
\hline \multicolumn{3}{|l|}{ Islet-related autoantibodies } \\
\hline GAD autoantibody $(\mathrm{U} / \mathrm{mL})$ & $<0.3$ & $0-1.4$ \\
\hline IA-2 autoantibody (U/mL) & $<0.4$ & $0-0.4$ \\
\hline Insulin autoantibody (\%) & $<0.4$ & $0-0.4$ \\
\hline ZnT8 autoantibody (U/mL) & $<10$ & $0-15$ \\
\hline \multicolumn{3}{|l|}{ Urinalysis } \\
\hline Ketone body & $3+$ & \\
\hline Protein & - & \\
\hline Albumin $(\mathrm{mg} / \mathrm{g} \cdot \mathrm{Cr})$ & 14 & \\
\hline \multicolumn{3}{|l|}{ Arterial blood gas analysis } \\
\hline $\mathrm{PH}$ & 7.33 & \\
\hline $\mathrm{PaO}_{2}(\mathrm{mmHg})$ & 108 & \\
\hline $\mathrm{PCO}_{2}(\mathrm{mmHg})$ & 36.7 & \\
\hline $\mathrm{HCO}_{3}^{-}(\mathrm{mmol} / \mathrm{L})$ & 19 & \\
\hline $\mathrm{BE}(\mathrm{mmol} / \mathrm{L})$ & -5.8 & \\
\hline \multicolumn{3}{|l|}{ HLA typing } \\
\hline HLA-A & \multicolumn{2}{|c|}{$A * 11: 01, A * 24: 02$} \\
\hline HLA-B & \multicolumn{2}{|c|}{$B * 35: 01, B * 54: 01$} \\
\hline HLA-DRB1 & \multicolumn{2}{|c|}{ DRB $1 * 04: 05$, DRB $1 * 08: 03$} \\
\hline HLA-DQB1 & \multicolumn{2}{|c|}{ DQB1*04:01, DQB1*06:01 } \\
\hline
\end{tabular}

$\mathrm{ng} / \mathrm{mL}$ and $0.90 \mathrm{ng} / \mathrm{mL}$, with no decrease of estimated glomerular filtration rates $\left(75-89 \mathrm{~mL} / \mathrm{min} / 1.73 \mathrm{~m}^{2}\right)$, for the duration of the follow-up period. Delta C-peptides levels after glucagon loading at $10 \mathrm{MPO}$ and $24 \mathrm{MPO}$ were $0.34 \mathrm{ng} / \mathrm{mL}$ and $0.63 \mathrm{ng} / \mathrm{mL}$, respectively, indicating substantial increases from that of $0.05 \mathrm{ng} / \mathrm{mL}$ at the onset (Table 2). His body weight remained stable at around $64 \mathrm{~kg}$ (Fig. 1B). His HbA1c levels were maintained at approximately $6.0 \%$ by means of MDI (approximately 1.0-1.2 $\mathrm{U} \cdot \mathrm{kg}^{-1} \cdot 24 \mathrm{~h}^{-1}$ ) (Fig. 1C-D). For precise evaluation, we assessed glycemic control by continuous glucose monitoring (CGM) using iPro2 ${ }^{\circledR}$ (Medtronic Japan) for two consecutive days at 10 MPO (Fig. 2), revealing that the average glucose level was $118.1 \mathrm{mg} / \mathrm{dL}$, the standard deviation (SD) of glucose levels was $35.8 \mathrm{mg} / \mathrm{dL}$ and the mean amplitude of glycemic excursions (MAGE) was $95.7 \mathrm{mg} / \mathrm{dL}$. 
A

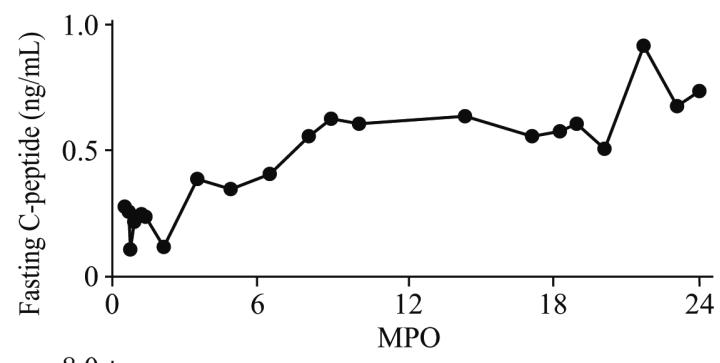

B

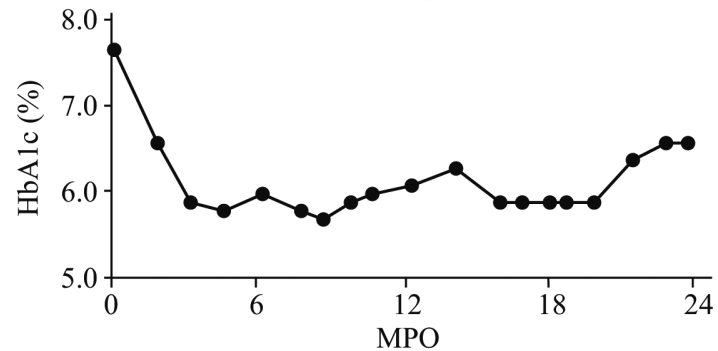

$\mathrm{C}$

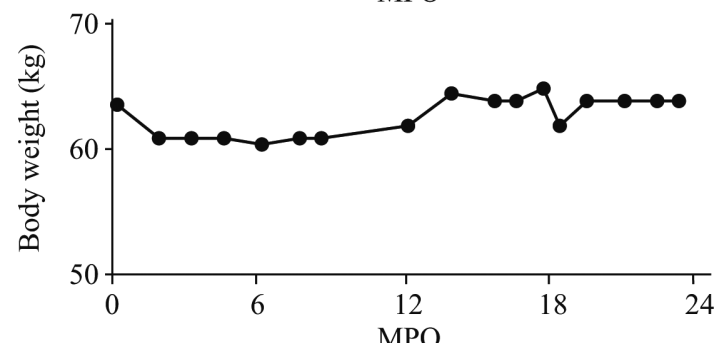

D

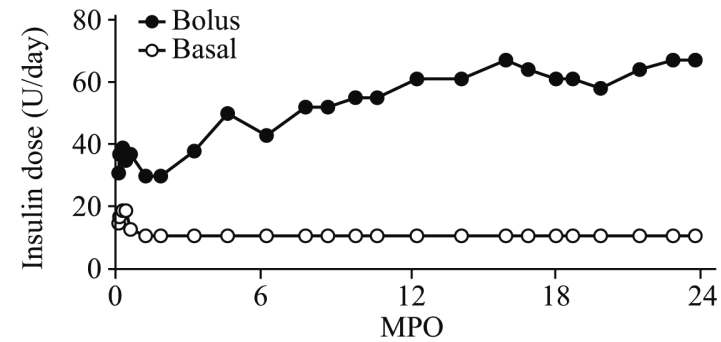

Fig. 1 The time course since diabetes onset

(A) Fasting C-peptide levels (ng/mL), (B) HbAlc (\%), (C) body weight $(\mathrm{kg})$, and (D) insulin doses (U/day). Bolus (closed circle) and basal (open circle) insulin doses are shown. $\mathrm{MPO}=$ months post onset.

\section{Discussion}

The patient presented herein experienced abrupt onset of diabetes with extremely low initial C-peptide levels but was spared complete loss of insulin secretary capacity and later showed substantial recovery.

Acute onset of ketosis such as in our case is typically regarded as type 1 diabetes. There is, however, a subtype of type 2 diabetes which presents with the acute onset of ketosis, as exemplified by "soft-drink ketosis" [6]. Patients with soft-drink ketosis have typically high insulin secretory capacity with obese phenotypes. In these patients, excessive sugar-rich soft drink intake is thought to induce severe $\beta$-cell dysfunction in a transient manner and reduction in the dose, or even discontinuation, of insulin is frequently feasible. Contrary to these clinical characteristics, our patient had no history of either obesity or excessive soft drink intake. His serum C-peptide levels were extremely low and long-term MDI therapy (more than 1.0-1.2 $\mathrm{U} \cdot \mathrm{kg}^{-1} \cdot 24 \mathrm{~h}^{-1}$ ) has been required to maintain good glycemic control. These clinical characteristics of our case are clearly different from those of the ketosis observed in type 2 diabetes. Based on these clinical characteristics of our present case, we concluded remarkable $\beta$-cell destruction, rather than $\beta$-cell dysfunction, to likely be the main cause of his diabetes, although no

Table 2 Glucagon stimulating test

\begin{tabular}{lccc}
\hline & At onset & 10 MPO & 24 MPO \\
\hline Fasting glucose $(\mathrm{mg} / \mathrm{dL})$ & 78 & 110 & 125 \\
Fasting C-peptide $(\mathrm{ng} / \mathrm{mL})$ & 0.11 & 0.61 & 0.59 \\
Delta C-peptide $(\mathrm{ng} / \mathrm{mL})$ & 0.050 & 0.34 & 0.63 \\
\hline
\end{tabular}

MPO, months post onset.

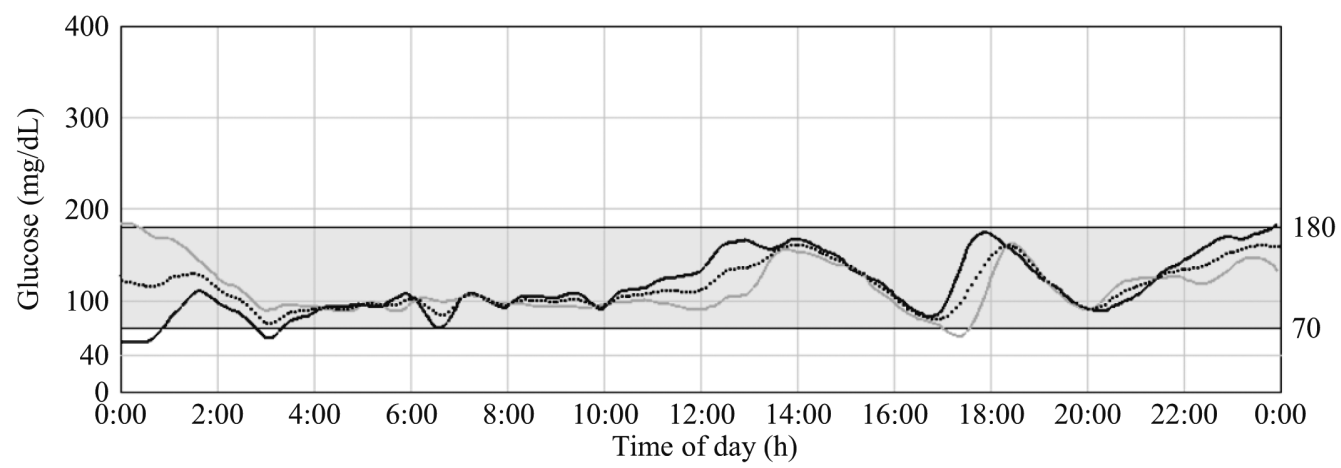

Fig. 2 Glucose level changes $(\mathrm{mg} / \mathrm{dL})$ at $10 \mathrm{MPO}$ determined with a CGM system for 24 hour per day over two consecutive days A dotted curve describes the mean glucose level changes of two days. 
direct evidence, including pathological findings, was available. Considering all islet-related autoantibodies were negative, our case can appropriately be categorized as having idiopathic type 1 diabetes.

Fulminant type 1 diabetes was proposed as a new subset of idiopathic type 1 diabetes [7] characterized by remarkably rapid and almost complete $\beta$-cell destruction [3]. In fulminant type 1 diabetes, remarkably acute and almost complete $\beta$-cell destruction occurs and nearly no insulin secretion remains, even just after the disease onset [5]. The established diagnostic criteria include high plasma glucose with relatively low $\mathrm{HbA1c}$ and an extremely low serum C-peptide level at the onset [4]. The clinical course is so rapid that a delay in the diagnosis may result in patient death. Thus, it is essential to promptly diagnose this disease at its onset. The time course of endogenous insulin secretion is not included among the diagnostic criteria, despite one of the common features observed in fulminant type 1 diabetes being a near-complete and prolonged deficit of insulin-secretory capacity [3]. Accordingly, serum C-peptide reportedly remains undetectable or persists at extremely low levels $(<0.30$ $\mathrm{ng} / \mathrm{mL}$ ) in patients with fulminant type 1 diabetes [5]. In our case, the clinical findings at the onset fulfilled the diagnostic criteria for fulminant type 1 diabetes. During the 24-month follow-up period, however, fasting serum C-peptide levels gradually increased, reaching a level as high as almost $1.0 \mathrm{ng} / \mathrm{mL}$. A similar case, whose insulin secretory capacity showed recovery after the initial diagnosis of fulminant type 1 diabetes, was reported previously [8]. In that earlier case, C-peptide level was below the detectable limit in the random sample obtained at the onset but then recovered to as high as $1.81 \mathrm{ng} / \mathrm{mL}$ four months after the initial diagnosis. The mechanism underlying substantial recovery of endogenous insulin secretion is unclear, since no pathological findings were available. Insulin secretion recovery may involve two possibilities, i.e. $\beta$-cell regeneration and restored function of $\beta$-cells which had been spared from destruction. As discussed above, $\beta$-cell destruction, rather than $\beta$-cell dysfunction, is likely to be the main cause of our patient's diabetes. Therefore, we consider $\beta$-cell regeneration to be the likely mechanism. Although still controversial, it was reportedly suggested that human islet cell proliferation is increased during the disease process in patients with recent-onset type 1 diabetes [9]. Therefore, a similar mechanism might also have contributed to the recov- ery of insulin secretion in our patient. On the other hand, even if a small population of $\beta$-cells had been spared from destruction, marked hyperglycemia at the onset may have caused glucose desensitization of such spared $\beta$-cells. We cannot rule out the possibility that restored function of these spared $\beta$-cells is involved in the recovery of endogenous insulin secretion. The important point is that the clinical courses of the previously reported case [8] and our present patient were quite atypical for fulminant type 1 diabetes.

There is another category of idiopathic type 1 diabetes with ketoacidosis, i.e. ketosis-prone diabetes. This form of diabetes is characterized by episodic ketoacidosis and insulin dependence at the time of diagnosis [10]. The categorization of fulminant type 1 diabetes reflects the rate and amount of pancreatic $\beta$-cell destruction at the onset, while the $A \beta$ classification scheme, based on the presence of autoimmunity $(\mathrm{A}+/-)$ and preserved $\beta$-cell function $(\beta+/-)$, has been verified as a subclassification for ketosis-prone diabetes. To evaluate $\beta$-cell function, C-peptide levels 12 months after diabetic ketoacidosis were utilized: fasting levels below $1 \mathrm{ng} / \mathrm{mL}$ or maximum glucagon-stimulated levels below $1.5 \mathrm{ng} / \mathrm{mL}$ were taken as $\beta-$ [11]. Considering the $A \beta$ classification scheme alone, our case might fall into the $A-\beta-$ category. However, his abrupt onset was quite atypical for ketosis-prone diabetes, since HbA1c levels at time of diagnosis are very high in such cases, more than $12.5 \%$ on average [10]. Thus, our case is characteristically different from fulminant type 1 diabetes and ketosis-prone diabetes.

Given the extremely abrupt onset, our case might represent a pathophysiology similar to that of typical fulminant type 1 diabetes at the onset, although the long-term clinical course differed. Both genetic and environmental factors have been suggested to contribute to the pathogenesis of fulminant type 1 diabetes [12]. As for the environmental factors, no elevations of viral antibodies were detected in our patient, but we cannot rule out the possibility of the involvement of other virus infections since the patient exhibited cold-like symptoms prior to the onset. As for genetic factors, class II HLA genotypes have been intensively analyzed in a large number of patients with fulminant type 1 diabetes. Our patient had not only a high-frequency haplotype (DRB1*04:05-DQB1*04:01), but also a low-frequency haplotype (DRB1*08:03-DQB1*06:01) (Table 1). However, none of the low-frequency haplotypes in combination with one of the high-frequency 
haplotypes reportedly contributes to protection from fulminant type 1 diabetes [13]. In addition, the patient had a class I HLA antigen, HLA-A24, which is reportedly associated with complete $\beta$-cell destruction in cases with insulin-dependent diabetes [14]. Although it is not clear how, or even whether, viral infection and the combination of HLA types were involved in the rapid progression of $\beta$-cell destruction in our case, these factors might have played a role in his unique clinical course.

The analysis of CGM in subjects with type 1 diabetes using MDI reportedly revealed that the average glucose level was $176 \mathrm{mg} / \mathrm{dL}$, the SD of glucose levels was $77 \mathrm{mg} / \mathrm{dL}$ and MAGE was $190 \mathrm{mg} / \mathrm{dL}$ [15]. Compared with the reported data, all of these glycemic control parameters in our patient were very low assessed by CGM at 10 MPO, indicating very stable control with relatively small glycemic fluctuations. However, the dose of injected insulin needed to maintain this glycemic control in our patient, 1.0$1.2 \mathrm{U} \cdot \mathrm{kg}^{-1} \cdot 24 \mathrm{~h}^{-1}$, was higher than that meeting the definition of either dose-defined partial remission $(0.5$ $\left.\mathrm{U} \cdot \mathrm{kg}^{-1} \cdot 24 \mathrm{~h}^{-1}\right)$ [16] or partial remission as defined by the insulin-dose-adjusted HbAlc (HbAlc (\%) + 4 [insulin dose $\left.\left.\left(\mathrm{U} \cdot \mathrm{kg}^{-1} \cdot 24 \mathrm{~h}^{-1}\right)\right] \leq 9\right)$ [17]. Therefore, our case was unlikely to be in the partial remission 'honeymoon' phase which is often achieved in patients with type 1a diabetes. The bolus insulin doses were gradually increased as the patient ate small meals more frequently after discharge. Even though augmented by insulin injections, this state with generally good glycemic control and relatively small glycemic fluctuations indicates that residual $\beta$-cells, spared from very rapid destruction, are indeed functioning in our patient.

Recently, diabetes has come to be considered a much more heterogeneous disease than the present subdivisions would suggest $[2,18]$. This case of idiopathic type 1 diabetes may provide novel insights into the heterogeneity of type 1 diabetes. Residual $\beta$-cell mass, even if small, is one of the critical factors not only for categorization of diabetes, but also for preventing glycemic fluctuations and thereby determining the long-term outcomes of type 1 diabetes patients. Therefore, further accumulation of such cases would contribute to clarifying the diversity of diabetes as well as identifying new strategies for protecting $\beta$-cells from complete destruction and/or promoting $\beta$-cell survival after severe $\beta$-cell damage at the onset.

\section{Disclosure}

The authors declare no conflict of interest associated with this manuscript.

\section{Contributions}

KK, CS, JY and HT were directly involved in care of the patient. SS, JI, TY and HK were consultants in the patient's care. KK prepared the draft of the report and HK reviewed and revised the report.

\section{References}

1. American Diabetes Association (2009) Diagnosis and classification of diabetes mellitus. Diabetes Care 32: S62-S67.

2. Tuomi T, Santoro N, Caprio S, Cai M, Weng J, et al. (2014) The many faces of diabetes: a disease with increasing heterogeneity. Lancet 383: 1084-1094.

3. Hanafusa T, Imagawa A (2007) Fulminant type 1 diabetes: a novel clinical entity requiring special attention by all medical practitioners. Nat Clin Pract Endocrinol Metab 3: 36-45.

4. Imagawa A, Hanafusa T, Awata T, Ikegami H, Uchigata Y, et al. (2012) Report of the Committee of the Japan Diabetes Society on the Research of Fulminant and Acute-onset Type 1 Diabetes Mellitus: New diagnostic criteria of fulminant type 1 diabetes mellitus (2012). $J$ Diabetes Investig 3: 536-539.

5. Shibasaki S, Imagawa A, Terasaki J, Hanafusa T (2010)
Endogenous insulin secretion even at a very low level contributes to the stability of blood glucose control in fulminant type 1 diabetes. J Diabetes Investig 1: 283-285.

6. Yamada K, Nonaka K (1996) Diabetic ketoacidosis in young obese japanese men. Diabetes Care 19: 671.

7. Imagawa A, Hanafusa T, Miyagawa J, Matsuzawa Y (2000) A novel subtype of type 1 diabetes mellitus characterized by a rapid onset and an absence of diabetes-related antibodies. Osaka IDDM Study Group. N Engl J Med 342: 301-307.

8. Yamashita K, Sato Y, Seki K, Asano J, Funase Y, et al. (2013) Fulminant type 1 diabetes with robust recovery of insulin secretion: A case report. Diabetes Res Clin Pract 100: e34-38.

9. Willcox A, Richardson SJ, Bone AJ, Foulis AK, Morgan NG (2010) Evidence of increased islet cell proliferation in patients with recent-onset type 1 diabetes. 
Diabetologia 53: 2020-2028.

10. Maldonado M, Hampe CS, Gaur LK, D’Amico S, Iyer $\mathrm{D}$, et al. (2003) Ketosis-prone diabetes: dissection of a heterogeneous syndrome using an immunogenetic and beta-cell functional classification, prospective analysis, and clinical outcomes. J Clin Endocrinol Metab 88: 5090-5098.

11. Balasubramanyam A, Garza G, Rodriguez L, Hampe CS, Gaur L, et al. (2006) Accuracy and predictive value of classification schemes for ketosis-prone diabetes. Diabetes Care 29: 2575-2579.

12. Imagawa A, Hanafusa T (2011) Fulminant type 1 diabetes - an important subtype in East Asia. Diabetes Metab Res Rev 27: 959-964.

13. Tsutsumi C, Imagawa A, Ikegami $\mathrm{H}$, Makino $\mathrm{H}$, Kobayashi T, et al. (2012) Class II HLA genotype in fulminant type 1 diabetes: A nationwide survey with reference to glutamic acid decarboxylase antibodies. $J$ Diabetes Investig 3: 62-69.

14. Nakanishi K, Kobayashi T, Murase T, Nakatsuji T,
Ionko H, et al. (1993) Association of HLA-A24 with complete beta-cell destruction in IDDM. Diabetes 42: 1086-1093.

15. Garg SK, Voelmle MK, Beatson CR, Miller HA, Crew LB, et al. (2011) Use of continuous glucose monitoring in subjects with type 1 diabetes on multiple daily injections versus continuous subcutaneous insulin infusion therapy: a prospective 6-month study. Diabetes Care 34: 574-579.

16. Chase HP, MacKenzie TA, Burdick J, Fiallo-Scharer R, Walravens P, et al. (2004) Redefining the clinical remission period in children with type 1 diabetes. Pediatr Diabetes 5: 16-19.

17. Neylon OM, White M, O'Connell MA, Cameron FJ (2013) Insulin-dose-adjusted HbA1c-defined partial remission phase in a paediatric population - when is the honeymoon over? Diabet Med 30: 627-628.

18. Merger SR, Leslie RD, Boehm BO (2013) The broad clinical phenotype of Type 1 diabetes at presentation. Diabet Med 30: 170-178. 